
1996, he took a position at the Dauphin Island Sea Lab, where he found that the US National Oceanic and Atmospheric Administration had years of mostly unprocessed population data on moon jellyfish (Aurelia aurita) and Atlantic sea nettles (Chrysaora quinquecirrha) in the Gulf of Mexico. These data were a rare treasure; only a handful of similar long-term records exist.

Graham discovered that from 1985 to 1997 , the jellies had grown substantially more widespread and abundant in several parts of the Gulf, and he suggested that human changes to the ecosystem might be the cause ${ }^{2}$.

Similar findings supported the notion. In the Bering Sea, one of the handful of locations with a monitoring record longer than a few years, jelly numbers had also risen through the 1990s. That matched predictions made by ocean scientists, who had warned that as humans degrade the oceans they are shifting ecosystems, reducing numbers of larger fish and promoting populations of organisms from lower down the food chain $^{3,4}$. Among the beneficiaries would be algae, toxic plankton and jellyfish - in other words, there would be a sea of slime.

\section{BOOM AND BUST}

The link between ocean degradation and jellyfish makes biological sense. Nutrient pollution can increase food supplies for jellyfish; overfishing can reduce their competition; and warmer temperatures are thought to trigger reproduction in some jellyfish species.

But as the slime paradigm gained traction in the literature, something odd was happening in the Gulf of Mexico. One of Graham's graduate students, Kelly Robinson, found that jellyfish numbers in the northern Gulf had declined for several years after 1997, and then rebounded. Her work has not yet been published.

Researchers studying jellyfish in the Gulf of Mexico and the Bering Sea now think that longterm natural climate cycles have an important role in controlling populations there. "Just seeing a lot of jellyfish does not say anything," says Graham now. "People say, 'Oh my God, the world is going to hell,' but jellies form blooms. That's what they're supposed to do." The challenge for researchers lies in separating normal fluctuations from those for which humans might deserve some of the blame.

Graham and others decided to take a scientific step back. In 2009, the National Center for Ecological Analysis and Synthesis at the University of California, Santa Barbara, funded Graham, Condon and Carlos Duarte, a marine ecologist at the Mediterranean Institute for Advanced Studies on Majorca, Spain, to establish the working group that has just published its findings. Made up of dozens of researchers, it compiled all the scientific data available on jellies worldwide. After a preliminary examination, the group said ${ }^{1}$ that it could not support the conclusion that jellyfish numbers are increasing globally, because only a few places have been monitored carefully and even there the data are limited.

Researchers have tended to ignore or avoid jellyfish, in part because they are such a nightmare to deal with. Typical nets shred them, and collecting them intact can require heroic efforts. Shin-ichi Uye, a marine ecologist at Hiroshima University in Japan, says that because some jellyfish are heavier than sumo

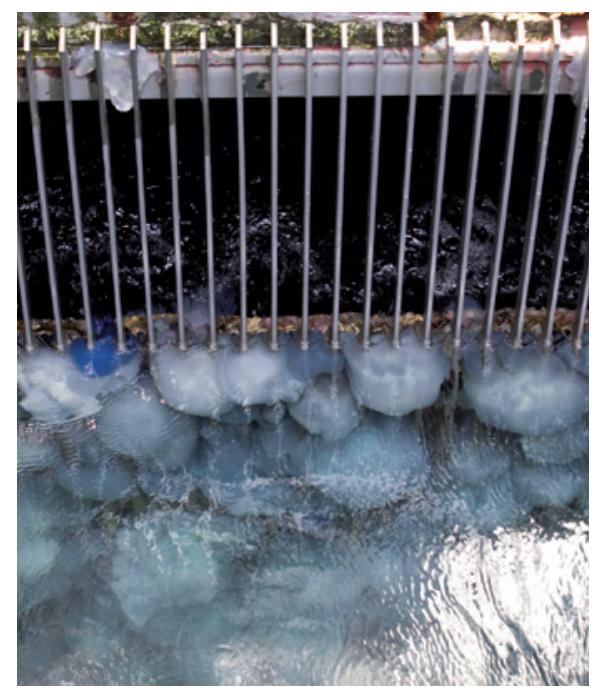

Jellyfish plagued an Israeli power plant in 2011.

wrestlers, marine biologists must carefully balance their small research boats to avoid capsizing when retrieving a single specimen.

To make matters worse, many jellyfish groups have complex life cycles. Several species, including moon jellyfish, reproduce sexually to form larvae that settle on the sea floor and develop into anemone-like growths called polyps. If conditions are favourable, a single polyp can bud to form 20 floating jellies. But in hard times, polyps can produce more polyps or retreat into a tough cyst. Then, when the environment improves, the waiting polyps can fuel a massive bloom of jellyfish that might seem like an invasion from nowhere.

With very few exceptions, the polyp colonies that cause large jellyfish blooms are "really hard to find", says Claudia Mills, a jellyfish specialist at the University of Washington's Friday Harbor Laboratories, who was part of the jellyfish review group and was one of the first to examine the possibility of a global rise. Bloom triggers seem to be tied to seasonal temperature changes, she says. And that raises the possibility that warming of the oceans could indeed cause populations to mushroom ${ }^{5}$.

Most of the researchers who have questioned the idea of a jellyfish explosion say they cannot rule out the possibility that blooms are becoming more prevalent or that humans are at least partly responsible 6 . In Japan, for example, longterm records suggest that blooms happened only every 40 years or so before 2000 , but have come nearly every year since ${ }^{7}$. Moreover, the blooms seem to originate in Chinese waters, where overfishing has severely depleted the Japanese jellyfishes' main competitors.

In most other cases, however, the trends are not so clear cut. So in 2010, the biologists on the task force began a Jellyfish Database Initiative (JEDI), compiling every scientific jellyfish record they could find, and they expect to continue expanding this resource. Some researchers are also teaming up with the public. The Monterey Bay Aquarium Research Institute in California has launched a website called Jellywatch.org, through which scientists and citizens can report jellyfish sightings to help fill out the JEDI database. The intergovernmental Mediterranean Science Commission in Monaco has started a similar programme for that sea.

\section{HIDDEN DATA}

Despite the lack of long-term studies, some scientists think that there is enough evidence to answer some important questions. In a paper due out later this month, Lucas Brotz, a graduate student in fisheries biology at the University of British Columbia in Vancouver, Canada, and his adviser, Daniel Pauly, analysed media reports and other non-scientific data about bloom patterns since 1950, such as interviews with locals and scientists. The researchers used fuzzy logic, a ranking system that incorporates the reliability and abundance of information, to identify trends in less-than-ideal data sets. They found that jellyfish populations were increasing in 31 of the 45 ocean regions that they studied.

"Our study says you can actually pierce through the confusing fog of press reports and anecdotes and scientific data to establish whether increases are occurring," says Pauly.

Graham and other researchers praise the approach, but they contend that such information just isn't adequate. The jellyfish review team will begin to analyse the full JEDI database later this month, encouraged by the growth of programmes in places such as Peru and Japan, where scientists work with fishermen to monitor jellyfish populations. But even so, the researchers caution that they will need to establish many more monitoring programmes to complete a global picture.

With such programmes in place, researchers could use the comprehensive jellyfish data sets to track how the oceans are changing. These creatures make ideal environmental sentinels because humans mostly leave them alone, says Graham. "Jellyfish are the great bystanders of the oceans and the oceans' health."

Mark Schrope is a freelance writer in Melbourne, Florida.

1. Condon, R. H. et al. BioScience 62, 160-169 (2012),

2. Graham, W. M. Hydrobiologia 451, 97-111 (2001).

3. Pauly, D., Christensen, V., Dalsgaard, J., Froese, R. \& Torres, F. Jr Science 279, 860-863 (1998).

4. Jackson, J. B. C. Proc. Natl Acad. Sci. USA 105, 11458-11465 (2008)

5. Mills, C. E. Hydrobiologia 451, 55-68 (2001).

6. Purcell, J. E. Annu. Rev. Mar. Sci. 4, 209-235 (2012).

7. Uye, S. Plankton Benthos Res. 3, S125-S131 (2008). 